\title{
ENTRE O VIVIDO E O PERCEBIDO: O SABER ESCOLAR E A REALIDADE DAS CRIANÇAS RIBEIRINHAS
}

\author{
Ronara Viana Cordovil ${ }^{1}$ \\ Paula Naranjo Da Costa ${ }^{2}$ \\ Huanderson Barroso Lobo ${ }^{3}$ \\ José Camilo Ramos de Souza ${ }^{4}$
}

\begin{abstract}
Resumo: O presente artigo abre uma discussão em torno do ensino escolar e do saber cotidiano apreendido e exercitado nos espaços de vivências das crianças ribeirinhas amazônicas. O percurso objetivou apresentar um panorama de como as crianças ribeirinhas estão rodeadas por conhecimento científico nas atividades de subsistência que realizam com os pais e que fazem parte do currículo escolar, mas que não é ressignificado dentro do espaço educacional porque não reflete a união dos dois saberes e nem é feito o caminho pelo qual o conhecimento percorre. Neste movimento abre-se reflexão sobre uma proposta de ensino através da interdisciplinaridade, com diálogos entre professores-professores e professores-estudantes que possibilita um saber abrangente e integral. O embasamento teórico que sustenta esta discussão se apoia em: Andrade (2013); Kaercher (2014); Pontuschka, Paganelli, Cacete (2007) e Castrogiovanni (2003) os quais apresentam posicionamentos em torno do saber construído na prática e no fazer cotidiano. Tal premissa abre possibilidades de integração com o saber apreendido dentro da escola e leva os estudantes a reflexão ampla de conceitos científicos, conduzindo-os a uma formação integral. Os caminhos metodológicos se prenderam em descrever as relações vividas nos caminhos da escola, no meio da mata e na beira do rio, pois nesse espaço de vida se constrói e se desenvolve o estudante de escola ribeirinha.
\end{abstract}

Palavras-Chave: Amazônia; Escola; Criança; Ribeirinho.

\section{BETWEEN THE LIVED AND THE PERCEIVED: SCHOOL KNOWLEDGE AND THE REALITY OF RIVERSIDE CHILDREN}

\begin{abstract}
The present article opens a discussion about the school teaching and the daily knowledge learned and practiced in the living spaces of the riverside children of the Amazon. The course aimed to present a panorama of how the riverside children are surrounded by scientific knowledge in the subsistence activities that they perform with the parents and that are part of the school curriculum, but that is not resignified within the educational space because it does not reflect the union of the two knowledge and the way by which knowledge travels is not made. In this movement, reflection on a proposal of teaching through interdisciplinarity, with dialogues between teachers-teachers and studentsteachers, that allows a comprehensive and comprehensive knowledge. The theoretical basis for this discussion is based on: Andrade (2013); Kaercher (2014); Pontuschka, Paganelli, Cacete (2007) and Castrogiovanni (2003) which present positions around the knowledge built in practice and in daily practice. This premise opens possibilities for integration with the knowledge learned within the school and leads students to broad reflection of scientific concepts, leading them to an integral formation. The methodological paths were focused on describing the relationships lived in the ways of the school, in the middle of the forest and on the edge of the river, because in this space of life is built and develops the school student riverside.
\end{abstract}

Keywords: Amazon; School; Child; Ribeirinho.

\footnotetext{
${ }^{1}$ Mestranda em Educação e Ensino de Ciências na Amazônia. Universidade do Estado do Amazonas Normal Superior - UEA/ENS, Brasil.

${ }^{2}$ Mestranda em Educação e Ensino de Ciências na Amazônia. Universidade do Estado do Amazonas Normal Superior - UEA/ENS, Brasil.

${ }^{3}$ Mestrando em Educação e Ensino de Ciências na Amazônia. Universidade do Estado do Amazonas Normal Superior - UEA/ENS, Brasil.

${ }^{4}$ Doutor em Geografia Física pela Universidade de São Paulo/USP. Professor do Curso de Geografia do Centro de Estudos Superiores de Parintins/UEA.
} 


\section{INTRODUÇÃO}

Este artigo fala sobre o caminho para se chegar ao saber numa discussão que reflete conhecimentos científicos presente no espaço acadêmico e escolar com os conhecimentos empíricos presente no cotidiano, convívio familiar, ambiental e social. Ambos os conhecimentos estão presentes na vida da criança enquanto ser histórico aprendiz do que lhe é ensinado, observado e vivido.

Reflete analiticamente o caminho que as crianças de comunidades ribeirinhas realizam até a escola (prédio), que são caminhos terrestres ou fluviais percorridos pelos estudantes por rios, lagos ou trilhas dentro da floresta; estes ribeirinhos todos os dias letivos de aula trafegam por estes espaços de vivência e conhecimentos, participando diariamente de aventuras e construindo saberes que passam despercebido na escola, pois não há ressignificação.

Estes caminhos percorridos até a escola, passam a serem visto apenas com entusiasmo e espanto do momento que é trafegado, porque não é participado na escola; local do "real conhecimento" onde o estudante deve prestar atenção para aprender, por ser importante para sua vida, sobrevivência e formação.

Essa concepção abre discussão em relação a aprendizagem e questionamentos sobre qual é o verdadeiro saber, é o que "está" dentro da escola, dos livros ou aquele que se vive e sabe; as construções históricas, os livros foram escritos e desenvolvidos a partir do que se vive e aprende pela observação do mundo físico e humano, repleto de fatos, notícias, ideias, que circundam a vida cotidiana das crianças ribeirinhas levando a adquirir saber, experimentar o mundo.

A escola do saber - o mundo apresentado aos olhos, vivido, percebido, com movimentação contínua relacionando a estrutura física (global) e humana (relações sociais, culturais, econômica, tecnológica) passa a ser encarado pelo estudante ribeirinho com desprendimento de ideias lógicas, objetivas, realizando leituras e apreensões da realidade, compreendendo o fazer e formando-se integralmente enquanto sujeito pensante, cidadã de direitos e habilidades importantes a sociedade.

O vivido e o percebido ações que se faz independentes da condução da escola, é um exercício mental do ser realizado a partir de sua existência, de se perceber dentro do mundo, participando e agindo sob as transformações físicas e emocionais. Um aprendizado que vai se construindo a partir do viver e do perceber numa constante 
reflexão das coisas, (re) significando os conhecimentos que recebe, aprecia, constrói e partilha com os pares o que viu e refletiu no movimento do olhar lindo analiticamente.

A (re) significação do observado na caminhada em busca de saber, está no exercício de observar e guardar o que se passa aos olhos e reutilizá-lo quando necessário na construção de novos saberes, unindo saber formal e saber comum, considerando experiências vivas e sentidas a partir da interpretação de vários fatores sociais, econômicos e ideológicos que influenciam o agir e o pensar numa primeira miragem.

Ler aquilo que se vê, é considerar que cada um pode interpretar de forma diferente um mesmo acontecimento ou fato a partir de sua experiência, em um sistema de significação, em espaços de socialização e diálogos para discutir ideias préconcebidas.

A busca do saber não se fecha ao que se recebe ou assimila quando se chega a escola, mas é uma construção que continuamente se faz durante a vida, porque o conhecimento não é conclusivo, fechado ou com limites a serem alcançados, é construído e mutável a cada linha de raciocínio que se restitui. Aprender, assim como o conhecimento está a todos os espaços de vivências que a criança participa dentro da sociedade que pode ser a família, igreja, quintal de casa, reuniões escolares, grupos de brincadeiras (jogos de futebol, corrida, amarelinha).

\section{ESPAÇOS DE VIVÊNCIAS E APRENDIZAGEM}

Dentro do convívio familiar é partilhado aprendizados, saberes, valores, e experiências empíricas advindos da tradição familiar que são reproduzidas por gerações. As crianças vindas de famílias que seguem experiências, conhecimentos, regras e condutas são conduzidas e direcionadas ao convívio harmônico e respeitável dentro do âmbito familiar.

Participando das manifestações culturais em família (reuniões, brincadeiras, tarefas diárias) as crianças são ensinadas a aprender as ocupações e a ajudar em trabalhos e tarefas em casa. Os pais assumem a postura de educadores, apresentando o que se deve fazer, ensinando valores, condutas e responsabilidades.

As responsabilidades na qual a criança é colocada, os afazeres domésticos e as atividades, contribuem para sua sobrevivência capacitando a criança intelectualmente às práticas cotidianas, que vai desde a resolução de problemas em casa e a ser disciplinado 
nas atividades domesticas que exigem força física e mental (a pesca, a caça, o trabalho na roça ${ }^{5}$ ), à aprendizagem de construções de objetos que auxiliam a busca de recursos naturais de subsistência como o caniço ${ }^{6}$ e a malhadeiras usados na pesca, como também os paneiros e o tipiti - utilizados para a transformação da mandioca na massa da farinha.

Nesse ir e vir de conhecimentos que circundam a criança, nas construções e nos ensinamentos repassados e apreendido na prática, envolve diversas áreas do saber científico; a construção do caniço, exige conhecimento de física (flexibilidade da madeira, resistência), biologia (a árvore, a preparação e manipulação), matemática (medida da vara e da linha, linhas e curvas) que são conhecimentos práticos com bases cientificas que subsidiem a vida da criança ribeirinha, que passa a exercitar diariamente numa compreensão do mundo a partir do que vive e concebe (participa).

Assim a criança vai se construindo intelectualmente com o contato direto com o mundo, com a natureza e com o fazer, aprendendo na prática conceitos e saberes que os envolve, interpretando fatos, fenômenos que dinamizam o funcionamento do mundo, dos fenômenos naturais e humanísticos. Conforme concorda Libânio apud Zannata (2005, p. 168):

A preparação da criança para vida futura deve basear-se no estudo das coisas que correspondem às suas necessidade e interesses atuais. Antes de ensinar as ciências, elas precisam ser levadas a despertar o gosto pelo seu estudo. Os verdadeiros professores são a natureza, a experiência e o sentimento. O contato da criança com o mundo que a rodeia é que desperta o interesse e suas potencialidades naturais.

Mesmo antes de ser inserida na escola para aprender fórmulas, desenvolver textos, conceitos geográficos e fatos históricos, a criança ribeirinha já é completa de conhecimentos práticos e pautáveis adquiridos com atuação no mundo, na natureza em que vive com os ensinamentos advindos dos pais e das gerações pretéritas, com suas próprias experiências e a dos familiares, apoiadas em conhecimentos empíricos, testados durante as tentativas e ensaios em ações práticas da vida que os levou a chegar a conclusões.

\footnotetext{
${ }^{5}$ Roça - sementeira entre o mato ou no terreno onde se roçou; terreno de lavoura; terreno plantado de mandioca; o campo [...] onde se cultivam hortaliças e frutas. In: BUENO, Francisco da Silveira. Dicionário Escolar da Língua Portuguesa. 11 ${ }^{\mathrm{a}}$. ed. $10^{\mathrm{a}}$ tiragem. Rio de Janeiro: FAE - Fundação de Assistência ao Estudante - Ministério da Educação, 1986

${ }^{6}$ Caniço - vara de pescar. In: BUENO, Francisco da Silveira. Dicionário Escolar da Língua Portuguesa. $11^{\text {a }}$. ed. $10^{\text {a }}$ tiragem. Rio de Janeiro: FAE - Fundação de Assistência ao Estudante - Ministério da Educação, 1986
} 
Esses saberes testados e pautáveis imprimem nas crianças o desejo de pesquisar despertando sua curiosidade para também ir em busca de respostas, o interesse pela descoberta; aguçadas elas partem para a procura de explicações de como o mundo funciona, formulando e testando hipóteses das ideias pré-concebidas a partir de suas convicções advinda das observações.

A observação base de reflexão para aprender o que os outros fazem, no convívio, concebendo cada detalhe da vida cotidiana e do oficio (trabalho e saber) dos pais, faz parte da construção intelectual das crianças, pois assim, conforme Klisys (2010, p. 19):

As crianças estão sempre "inaugurando" experiências acerca do mundo e encarando esses aprendizados com muita curiosidade e dedicação. Constantemente elas formulam hipóteses, frutos de suas observações, explorações e de seu contato com o ambiente que as cerca. Quando as crianças têm condições de compartilhar esses aprendizados nas brincadeiras, experimentam uma integração muito maior com aquilo que estão aprendendo.

Essa integração vai refletindo nas experiências que buscam viver a partir do que observam, passando a realizar suas próprias construções que vai a criação de utensílios para atividades cotidianas à brinquedos com os quais exercitam através da imaginação os ofícios ensinados por seus pais. A vara de pesca improvisada no quintal (representa rio) na qual as folhas secas das árvores representam o peixe; a caça, com cabo de vassoura representação da espingarda ${ }^{7}$ e as galinhas e os cachorros a caça; são atividades que despertam o interesse das crianças, pois exigem movimento, desafio e estratégia; pelo processo de busca e mistério incutido nestas atividades as crianças são reportadas a pensar as dúvidas: o que vai ser pescado ou caçado, como vai fazer, como deve agir se preparar.

As criações práticas de saber exercitados através do exercício do brincar, como também a atividade da pecuária praticado pelas famílias ribeirinhas a qual consiste na criação de animais com objetivo de produzir alimentos, matérias primas e utilização de transporte de pessoas e mercadorias (cavalo e éguas). As crianças se conectam ao fazer para aprender, neste caso ser "vaqueiros", de cuidar e prender o gado, que são atividades "perigosas" e que não podem estar totalmente inseridas pelo perigo em lidar com os animais e por não terem ainda idade e maturidade suficiente para esse trabalho,

${ }^{7}$ Espingarda - carabina; arma de fogo de cano longo, portátil, de maior uso na caça. BUENO, Francisco da Silveira. Dicionário Escolar da Língua Portuguesa. 11ª . ed. 10ª tiragem. Rio de Janeiro: FAE - Fundação de Assistência ao Estudante - Ministério da Educação, 1986 
mas estão a observar e auxiliar os pais com pequenos atos (fechar a porteiras, segurar os cabrestos, levar as vasilhas do leite), assim são despertadas para construir suas próprias fazendas imaginativas com frutos das mangas que espetam com palitos colocando as patas e os chifres, montando os cercados, currais, porque gostam, e são entusiasmadas pela atividade.

$\mathrm{Na}$ medida que brinca e exercita aprende, significa e ressignifica o ato de fazer desenvolvendo técnicas e práticas de como agir na atividade real, e, esse processo envolve saber científico e teórico que passam desapercebido do olhar da criança estudante. Fonseca $(2001$, p. 28$)$ avalia da seguinte maneira: “[...] as novas formas de perceber e de elaborar informação tendem a otimizar-se, garantindo ao indivíduo disponibilidade para aprender a aprender, aumentando o poder da sua mente e do seu potencial de adaptabilidade".

Ao elaborar novas formas de perceber o fazer e organizar as informações construídas através do brincar a criança ribeirinha vai adquirindo saber, porque segundo Andrade (2013, p. 36) "brincar é um ato de fazer história com bases firmadas em fatos que constituem parâmetros para que o indivíduo crie saber e conhecimento sobre o mundo em que vive; isso se constitui num ato de criação".

A ação da criança ribeirinha dentro do convívio familiar a faz construir sua própria história pelas interpretações e participações nas atividades que desenvolve junto a família no mundo em que vive, levando a conceber a realidade e apropriar dos conhecimentos que a cerca. Andrade (2013, p. 45) destaca as condições para se chegar ao conhecimento do mundo:

Ler o mundo significa apropriar-se do conhecimento, bem como refletir sobre o seu mundo, sendo que a curiosidade deve ser destacada como precondição do conhecimento. O lúdico, compreendido como integrante desse meio (realidade), possibilita aos sujeitos criar, modificar, reestruturar as brincadeiras, os jogos, as regras de funcionamento.

A curiosidade da criança é condição fundamental para levá-la ao conhecimento, porque tem necessidade de saber para conhecer, e o conhecer não se dá apenas pelo observável, mas com o tocável, com a reflexão, imaginando-se nas atividades; pois, "não basta olhar; é preciso ver a natureza para com ela aprender. Não basta escutar; é preciso ouvir o pulsar humano para que os corações e mentes entrem em sintonia. Não basta pegar; é preciso tocar [...] a melodia da fraternidade" (LIMA, 2002, p. 165). 


\section{SABERES QUE NÃO SE COMUNICAM: O ESCOLAR E O VIVIDO}

Dialogar sobre os saberes existentes nas comunidades é procurar entender porque não se comunicam apesar de estarem juntos, tanto o escolar quanto o vivido. $\mathrm{O}$ escolar tem como base o conteúdo definido a partir de uma matriz curricular oficial e o vivido tem seu alicerce no ensinado nas relações e práticas cotidianas.

A criança ribeirinha aprende nos espaços de vivências, convivendo com ensinamentos e experiências que possibilitam construções de conhecimentos sobre o mundo, a cultura, a história. A escola como espaço de saber formal, ensina através do livro conteúdo das ciências dentro de uma proposta curricular organizada em disciplinas: Matemática, Geografia, História, Português, Artes e Ciências. Conforme cita Kimura (2014, p. 22):

[...] esses livros adiantam as estratégias didáticas a serem desenvolvidas para que o tema em pauta seja vencido. Com frequência surgem comentários de que são livros bastante ativos e há quem os considere pautados pelo construtivismo. [...] os encaminhamentos já estão determinados e explicitados. Cabe apenas aos alunos lerem os textos, realizarem as atividades e acompanharem as estratégias didáticas indicadas.

A organização dos conteúdos por meio de disciplinas ajuda os professores a sistematizarem atividades e exercícios que os ajudarão a conduzir os estudantes a aprendizagem. Com leituras de textos informativos e explicações orais, impulsionam as crianças a ler e aprender saberes construídos em tempos pretéritos e concepções históricas de cientistas e estudiosos a respeito do mundo em que vivem.

A visão de mundo construída através da relação educativa professor-estudante se fecha na interpretação dos conteúdos dentro do livro didático por meio da seleção e condução do estudante a uma formação limitada do saber, por ser tomado como conteúdo a visão de outrem. Nessa relação educativa as crianças aprendem os conteúdos mas não os ressignifica no seu fazer cotidiano; não consegue relacionar o saber escolar com o saber da prática abrindo diálogos para construir saberes amplos sobre o mundo, a sociedade, as relações sociais que os possibilitaria compreender seu papel de cidadã enfatizado por exercícios mentais de pensar e interpretar o mundo na sua própria visão analisando fatos e construindo sua história. Esse exercício constante do pensar, perceber sua existência e identidade dentro de um espaço é pura geografia, segundo afirma Kaercher (2014, p. 21): 
Pensar o ser humano implica pensar nos espaços que habitamos e transformamos, permanentemente, para que nossa existência possa acontecer, continuar. Existir implica, necessariamente, fazer geografia, transformar a natureza em espaços cotidianos".

Os estudantes ribeirinhos tem um contato íntimo com a natureza, porque ela faz parte de seu cotidiano diariamente, ao percorrer um caminho por dentro da mata, das plantações dos pais para se chegar a comunidade onde tem acesso à escola, ou ao pegar uma canoa e ir colocar a malhadeira n'água para pegar os peixes que lhes servirão de almoço e janta. As crianças transformam a natureza no seu fazer diário nas atividades que desenvolvem no contexto familiar, assim também exercitam mesmo sem saber os conhecimentos científicos.

Todos os saberes que a escola ensina e apresenta está presente no cotidiano e é vivenciando e transformado diariamente pelos estudantes. O conhecimento vai se construindo na/pela relação que o ser constrói nos espaços de vivências que pode ser o ambiente fechado da sala de aula quando refletido numa perspectiva de construção de saber, e, onde é manifestado diversas culturas e identidades, ou, na família, onde o saber prático, empírico circunda a vida da criança. A construção do saber e a aprendizagem se dar com inserção direta na prática, no fazer e pensar que são ações indissociáveis, segundo Kimura (2014, p. 46-47):

A aprendizagem pode ser entendida como o processo pela qual o ser humano percebe, experimenta, elabora, incorpora, acumula as informações da realidade transformadas em conhecimento. O ser humano desenvolve esse processo em diferentes patamares através de um fazer em sua relação com o mundo. Ele interioriza e incorpora as informações, elaborando cumulativamente o acervo do seu universo sociocultural e do seu organismo natural [Grifo nosso].

O fazer e o pensar ações incutidas nos saberes existentes na vida da criança se resume ao saber formal e o saber das práticas cotidianas, que são indissociáveis um do outro, por estarem totalmente conectados no ensinar e no fazer. O que escola ensina de conteúdo sobre o mundo em forma de fórmulas, cálculos, textos informativos, regras, atividades de escrita (exercícios e provas) e leitura, a criança apreende fazendo na prática e nas vivências diárias observando e participando do ofício familiar (pesca, caça, plantação) e com seus pares através de brincadeiras e jogos.

A matemática, na escola a criança aprende as quarto operações básicas, resoluções de cálculos, fórmulas, comprimento e medidas, linhas e curvas; no convívio 
familiar e nas vivências extraescolar ela aprende a remar ${ }^{8}$ atividade realizada na pescaria, ao remar ela cria mentalmente um sistema de retas, ângulos que faz a canoa andar e seguir a direção exigida sem bater na beira da canoa para não fazer barulho (assustar os peixes). E não é só a matemática que está incutida no movimento do remar, outras ciências como: a física - força, aceleração, impulsão e resistência; Biologia - os processos de obtenção de energia (Fotossíntese e respiração celular), ventos, suor; Geografia - região, direções: verticais e horizontais, direções dos ventos. São conhecimentos que a criança tem mas não faz relação com o que apreende na escola.

Porque há um distanciamento entre os dois conhecimentos, saber escolar e prático, e a escola através dos professores poderia possibilitar essa aproximação com a ressignificação dos conhecimentos que a criança tem, para que a partir daí desse continuidade nestes saberes em aplicabilidades práticas nos espaços de vivências. Da forma que está se configurando, com lacunas e divisões disciplinares, a escola passa a ser forjada de muito conteúdo, mas pouco reflexividade (KAERCHER, 2014).

Essa resistência em aproximar o escolar e o vivido, pode estar nas dificuldades profissionais em realizar a interligação entre a ação e a reflexão, com transposições didáticas dos conteúdos para melhor entendimento dos estudantes, ou na exigência que essa união permite que está em trabalhar em práticas pedagógicas interdisciplinares. $\mathrm{Na}$ qual, Pontuschka, Paganelli e Cacete (2007, p. 145) apresentam certas exigências ao professor:

O professor de uma disciplina específica como uma atitude interdisciplinar abre a possibilidade de ser um professor-pesquisador porque deve selecionar os conteúdos, métodos e técnicas trabalhados em sua disciplina e disponibilizá-los para contribuir com um objeto de estudo em interação com os professores das demais disciplinas. Isso não pode ser realizado sem uma pesquisa permanente.

A interdisciplinaridade não é fácil de aplicar, porque ela é equivalente ao trabalho coletivo, diálogos entre os professores de outras áreas deve ser permanente para que um possa ajudar o outro a compreender pontos específicos de cada área do conhecimento. A criança ribeirinha vive cercada de saberes científicos e interdisciplinares oriundo das experiências que observa e das práticas cotidiana que faz e constrói embasadas em diversas áreas da ciência, e, na escola persiste o ensino de forma parcelada.

\footnotetext{
${ }^{8}$ Remar: Impelir com auxílio dos remos; mover os remos para dar impulso a um barco. BUENO, Francisco

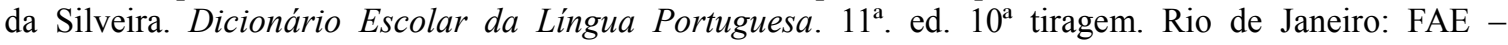
Fundação de Assistência ao Estudante - Ministério da Educação, 1986.
} 
Ao se pensar a escola como ambiente que propicia aprendizagens diversas, imagina-se que neste espaço circula as diversas ciências, culturas e histórias e, assim o estudante é ensinado de forma sistematizada, ressignificando os diferentes saberes, não de forma separada em disciplinas na qual aprende primeiro uma depois outra, mas interdisciplinar, juntas levando o estudante a uma formação integral. Mas, Castrogiovanni (2003, p.33) percebe que:

Há uma incapacidade da escola em propiciar situações que levem os alunos a constantes movimentos entre o codificar e o decodificar, o criar e o ler, o interpretar e o imaginar situações, fatos, dados, enfim, a vida. A escola, e, portanto, a geografia, continua distante da vida [Grifo nosso].

A escola se distancia do estudante ao pôr de lado o que ele vive e aprende nas práticas cotidianas, esse distanciar faz com que o estudante continue sem perceber os conhecimentos científicos dentro do seu fazer, interligando o conhecimento prático (do cotidiano) e o conhecimento teórico (escolar). Desconsiderando o saber em sua amplitude e multidisciplinar que se apresenta ao estudante nas suas construções cotidianas e nos conteúdos escolares.

\section{CONSIDERAÇÕES FINAIS}

A caminhada na floresta vivida e realizada pelo estudante com muito conhecimento do lugar, tornando a natureza parte de seu cotidiano, transformada diariamente por suas ações que modificam a paisagem, e no qual este fazer nas mãos dos estudantes ribeirinhos sempre é rodeado e perpassa por muitos conhecimentos científicos que não chega (ou até chega) na escola mas passa desapercebido por que não há ressignificação do que se aprende tanto na escola quanto no cotidiano.

Essa discussão analítica é enriquecedora por apresentar pontos no qual o ensino escolar é dissociado da realidade do estudante, principalmente das crianças ribeirinhas, que vivem e experienciam nas diversas atividades de subsistência familiar cotidiana conhecimentos da proposta escolar.

Mostra na trilha percorrida pelos estudantes a gama de conhecimentos geográficos, históricos e matemático que transcrevem ao observar e vivenciar fatos corriqueiros da vida dos animais, como das aves e dos gatos selvagens. Ou seja, estão cercados de saber e o exercitam no fazer, mas não ressignificam, não unem os dois 
conhecimentos (prático e teórico) no que fazem em atividades cotidianas e nem em atividades escolares porque não há a preparação do pensar e do olhar.

Perde-se na escola em se fazer um ensino interdisciplinar, porque há dificuldade em diálogos entre professores-professores e estudantes-professores, que poderiam selecionar e sistematizar a partir do coletado nas conversas um saber mais abrangente e integral, que possibilitaria construções de conceitos mais amplos associando a realidade vivida e percebida.

O exercício de percepção é constantemente realizado pelas crianças ribeirinhas por estarem em contato direto com a natureza e experienciando fazeres dos pais e familiares, mas a sua não exploração e entendimento desta atividade a faz ser uma atividade qualquer perdendo em conhecimento no sentido de que se poderia aprender e construir muito mais conceitos e saberes mais facilmente com direcionamento que permitiria observar e olhar com atenção e amplitude.

\section{REFERÊNCIAS}

ANDRADE, Simei $\mathrm{S}$. O lúdico na vida e na escola: desafios metodológicos. 1. ed. Curitiba: Appris, 2013.

CASTROGIOVANNI, Antônio C. O misterioso mundo que os mapas escondem. In: CASTROGIOVANNI, Antônio $\mathrm{C}$ [et al]. Geografia em sala de aula: práticas e reflexões. 4. Ed. Porto Alegre: Editora da UFRGS / Associação dos Geógrafos Brasileiros - seção Porto Alegre, 2003.

FONSECA, Vitor. Aprender e reaprender: educabilidade cognitiva no século 21. São Paulo: Editora Salesiana; Educação, Aprendizagem e Cognição, 2001.

KAERCHER, Nestor A. Se a Geografia escolar é um pastel de vento o gato come a Geografia Crítica. Porto Alegre: Evangraf, 2014.

KIMURA, Shoko. Geografia no ensino básico: questões e propostas. 2. ed. $3^{\text {a }}$ reimpressão. - São Paulo: Contexto, 2014.

KLISYS, Adriana. Ciência, arte e jogo: projetos e atividades lúdicas na educação infantil. São Paulo: Petrópolis, 2010.

LIMA, Luciano C. O sentido é o meio - ser ou não ser. In: PONTUSCHKA, Nídia N; OLIVEIRA, Ariovaldo U. (Orgs). Geografia em Perspectiva: ensino e pesquisa. São Paulo: Contexto, 2002.

PONTUSCHKA, Nídia N., PAGANELli, Tomoko I., CACETE, Núria H. Para ensinar e aprender Geografia. 1 ${ }^{\mathrm{a}}$. Ed. São Paulo: Cortez, 2007. 
ZANATTA, Beatriz A. O método Intuitivo e a percepção sensorial como legado de Pestalozzi para a Geografia escolar. In: Cad. Cedes, Campinas, vol. 25, n. 66, p. 165184, maio/ago. 2005. Disponível em: <http://www.cedes.unicamp.br>. 